\title{
Opioid prescriptions for pain and epidemic of overdose death: can the dramatic reduction in anesthesia mortality serve as an example?
}

This article was published in the following Dove Press journal:

Journal of Pain Research

28 June 2016

Number of times this article has been viewed

\section{Igor Kissin}

Department of Anesthesiology, Perioperative and Pain Medicine, Brigham and Women's Hospital, Harvard Medical School, Boston, MA, USA
Correspondence: Igor Kissin

Department of Anesthesiology,

Perioperative and Pain Medicine, Brigham and Women's Hospital, 75 Francis Street, Boston, MA 02II5, USA

$\mathrm{Tel}+\mathrm{I} 6177325052$

Fax + I6177340682

Email ikissin@bwh.harvard.edu

\begin{abstract}
The annual number of US deaths from prescription-opioid overdose quadrupled between 1999 and 2010 and in 2010 alone reached 16,651. Deaths from opioid overdose have now surpassed the historic death toll from another drug-related epidemic - anesthesia mortality. In 1954, Beecher and Todd published reliable data on anesthesia-related mortality in the US, estimating the annual number of deaths to be nearly 5,000. Presently anesthesia/anesthetics are reported as the underlying cause in approximately 34 deaths in the US annually. This spectacular decline in anesthesia-related mortality could serve as an example for attempts to curb the epidemic of opioid overdose death. The main reason that led to the dramatic decline in anesthesia-related mortality is the context in which anesthetics are used. It includes training of the anesthesia providers, the introduction of specific standards of patient safety, and anesthesia monitoring. I suggest that the introduction of a similar multifactorial proper context for the use of opioids in the treatment of chronic nonmalignant pain might be the same "game changer" it was for safety in anesthesia.
\end{abstract}

Keywords: chronic pain, addiction, opioid-use disorder, treatment compliance, apprenticeship, metrics of opioid effectiveness, aberrant opioid-related behavior

\section{Introduction}

The number of US deaths from prescription-opioid overdose quadrupled between 1999 and 2010 and in 2010 alone reached $16,651 .{ }^{1}$ Nevertheless, despite multiple preventive actions on many levels, the number of deaths continues to grow. According to some estimates, in 2014 the number of all opioid overdose deaths in the US increased to $28,647 .{ }^{2}$ The annual opioid death toll cannot be attributed purely to opioids - as the vast majority of these cases are found to have other central nervous system depressants in their systems. ${ }^{1}$ Deaths from opioid overdose have now surpassed the historic death toll from another drug-related epidemic - anesthesia-related deaths. In 1954, Beecher and Todd ${ }^{3}$ published reliable data on anesthesia-related mortality in the US, estimating the number of deaths to be nearly 5,000 (Table 1). Since then the number of anesthesia-related deaths rapidly declined from one in 1,000 anesthesia procedures in the 1940 s to one in 10,000 in the 1970 s, and to one in 100,000 in the 1990 s and early $2000 \mathrm{~s} .{ }^{4}$ Anesthesia/ anesthetics are reported presently ${ }^{4}$ as the underlying cause in approximately 34 deaths in the US annually. Although the differences between these two types of mortalities are very profound, the spectacular decline in anesthesia-related mortality could serve as an example for attempts to curb the epidemic of opioid overdose death. I suggest that at least three factors led to the dramatic decline in anesthesia-related mortality and might 
Table I Estimates of annual number of US deaths: anesthesia vs prescription-opioid overdose

\begin{tabular}{lll}
\hline Drug-related epidemics & 1943-1954 & 1999-2005 \\
\hline Anesthesia-related deaths & $5,100^{3}$ & $34^{4}$ \\
Prescription-opioid overdose deaths & no data & $16,651(2010)^{15}$ \\
\hline
\end{tabular}

be relevant to the fight against the prescription-opioid overdose epidemic: 1) focus on the mechanisms underlying high mortality that are the most modifiable by preventive actions; 2) establish apprenticeships for providers; and 3) broaden the use of specific monitoring techniques.

\section{Focus}

One of the best anesthesia-related examples on how to focus on the most accessible problems is found in a study by Beecher and Todd. ${ }^{3}$ The authors focused on a sixfold increase in anesthesia mortality in patients who received a myorelaxant (tubocurarine). This reflected a lack of understanding at the time of the pharmacology of neuromuscular blockade, especially the residual postoperative blockade that impairs the ventilatory drive. The answer to this problem came in the form of monitoring. Various methods of myorelaxation monitoring were developed, and their introduction coincided with a profound reduction in anesthesia-related mortality between the pre-1970s and the 1970s-1980s.

Efforts to curb the current epidemic of opioid overdose deaths have focused mainly on nonmedical use of opioids; a very important aim has been described-opioid addiction that occurs in both the medical and nonmedical setting. ${ }^{1}$ At the same time, a key precursor of opioid-related morbidity was - and still is - the use of opioids for the treatment of chronic nonmalignant pain. The history of opioid consumption confirms the crucial role in this epidemic of the opioid treatment of chronic pain. The use of opioids increased gradually in the second half of the 1980s, began to accelerate in the 1990s, and then - has risen precipitously since 2000 . This coincides with multiple recommendations of various medical organizations for more aggressive use of opioids for chronic nonmalignant pain. ${ }^{1}$ Such recommendations appeared since 1986, when the requirements for evidence-based approaches were not yet firmly established. However, there is presently no reliable evidence that long-term ( $>6$ months) opioid therapy for chronic pain is effective. ${ }^{5-7}$ In addition to the lack of real evidence that the long-term treatment of chronic pain with opioids is effective, the addictive nature of opioids was not properly exposed. The best illustration for this might be a conclusion in a 2006 article on iatrogenic opioid addiction:
[...] it is not known whether the risk for iatrogenic addiction among patients treated with opioids for acute or subacute pain is relatively high $(>10 \%)$ or low $(<0.1 \%){ }^{8}$

Although the incidence of iatrogenic opioid addiction is unknown, opioid use disorders are quite prevalent among chronic pain patients. A survey on the lifetime prevalence of prescription opioid use disorder among 705 chronic noncancer pain patients based on the Diagnostic and Statistical Manual of Mental Disorders (DSM)-5 revealed the degree of spread of abuse-related behavior $-35 \%$ of these patients met $D S M-5$ criteria. ${ }^{9}$ This indicates that reduction in the use of opioids for the treatment of chronic nonmalignant pain could profoundly reduce the number of addicted patients. The first step to counteract the epidemic should be efforts to reduce the number of new patients with chronic nonmalignant pain who are maintained on long-term opioids. Addiction has not yet developed at this point, therefore reductions should be more significant than from the treatment of addiction (usually requiring life-long efforts). The limitation of unnecessary use of opioids for the treatment of chronic pain could provide a very significant reduction of overdose opioid death rate through prevention of potentially addictive treatment.

\section{Apprenticeship}

Due to the relatively small number of pain medicine specialists, nonspecialists (mostly primary care providers) are left to manage some of the most complex patients with chronic pain. The analogous situation in anesthesia is the administration of moderate (conscious) sedation by non-anesthesia providers when there is the increased risk of morbidity and mortality (in such areas as endoscopy, dentistry, etc). To administer conscious sedation, a non-anesthesia provider needs a permit that requires more than a didactic course on the topic. For example, before it issues a permit to administer dental conscious sedation, the Connecticut Department of Public Health requires that the applicant (among other more stringent alternatives) have ten documented clinical cases utilizing "parenterally administered conscious sedation" (http://www. ct.gov/dph/cwp/view.asp?a=3121\&q+289282). This example from anesthesia safe practices implies that long-term (longer than 6 months) treatment of chronic nonmalignant pain should be provided by certified pain medicine specialists; or at least physicians who, in addition to the required didactic course, completed some type of apprenticeship during which they closely interacted for some time with providers who are actually practicing adequately controlled treatment. 


\section{Monitoring}

Advances in anesthesia monitoring were among the most important prerequisites for the dramatic decrease in anesthesiarelated mortality and morbidity. Improvements were multifocused, continuous, and concentrated mostly on prevention of adverse cardiovascular and respiratory events..$^{10}$ Monitoring can also be an important factor in the prevention of opioid overdose death in the treatment of chronic pain mainly through identifying patients who exhibit aberrant drug-related behavior. A number of screening tools have been developed in this regard. These tools usually assess correlates of opioid misuse such as mood disorder, abuse history, and past behaviors. There are also monitoring approaches that directly assess ongoing opioid adherence among chronic pain patients, such as the opioid compliance checklist. ${ }^{11}$ A number of objective indicators of prescription-opioid misuse such as periodic urine toxicology screens are very reliable. The problem is that most physicians providing opioid prescriptions simply do not have enough time and experience to properly administer these monitoring tools. ${ }^{11}$

In addition, it is difficult to monitor the pain-relieving effect of opioids, because their benefits in many patients are questionable, especially when opioids are used for a long time ( $>6$ months). It is possible that the usual metrics of analgesic effectiveness, such as pain intensity, might not be the best measure of success in chronic pain treatment. Other measures of opioid effectiveness that address the suffering and disability aspects of chronic pain might be more appropriate. ${ }^{12}$ Monitoring various indices of patient quality of life and disability might be of major importance in assessing the balance between the risk of aberrant opioid-related behavior and the benefits of continuing treatment.

\section{Conclusion}

The main reason for the dramatic decrease in anesthesiarelated mortality is the context in which anesthetics are used. It includes training of the anesthesia providers, the introduction of specific standards of patient safety, and anesthesia monitoring. ${ }^{13}$ As far as this can be used as an example to deal with the epidemic of prescription-opioid deaths, only the following three factors have been discussed here: 1) focus on reduction of the number of new patients with chronic nonmalignant pain who are maintained on long-term opioids; 2) need of an apprenticeship for providers of chronic opioid treatment; and 3) close monitoring of chronic nonmalignant pain patients for aberrant opioid-related behavior.

In general, the move from the current situation with opioid overdose death requires a multitude of various changes. They are best summarized in 12 recommendations of the Centers for Disease Control and Prevention (CDC) regarding opioid medications for chronic pain. ${ }^{14}$ On March 15, 2016, the CDC released a "Guideline for Prescribing Opioids for Chronic Pain" to chart a safer way of using opioids for chronic pain. One of the main CDC principals is that non-pharmacologic therapy and non-opioid pharmacologic therapy are preferred for chronic pain. ${ }^{7}$ Although prevention of addiction development is a great challenge, the opioid addiction treatment is an even greater problem. The enormous magnitude of it is determined by two factors: treatment of the addiction usually requires life-long efforts, ${ }^{15}$ and the number of addicted persons is extremely high (may exceed 5 million in the US). ${ }^{1}$

\section{Disclosure}

The author reports no conflict of interest in this work.

\section{References}

1. Kolodny A, Courtwright DT, Hwang CS, et al. The prescription opioid and heroin crisis: a public health approach to an epidemic of addiction. Annu Rev Public Health. 2015;36:559-574.

2. Kharasch ED, Brunt LM. Perioperative opioids and public health Anesthesiology. 2016;124(4):960-965.

3. Beecher HK, Todd DP. A study of the deaths associated with anesthesia and surgery: based on a study of 599, 548 anesthesias in ten institutions 1948-1952, inclusive. Ann Surg. 1954;140(1):2-35.

4. Li G, Warner M, Lang BH, Huang L, Sun LS. Epidemiology of anesthesiarelated mortality in the United States, 1999-2005. Anesthesiology. 2009; 110(4):759-765.

5. Kissin I. Long-term opioid treatment of chronic nonmalignant pain: unproven efficacy and neglected safety? J Pain Res. 2013;6:513-529.

6. Cou R, Turner JA, Devine EB, et al. The effectiveness and risks of long-term opioid therapy for chronic pain: a systematic review for a National Institutes of Health Pathways to Prevention workshop. Ann Intern Med. 2015;162(4):276-286.

7. Dowell D, Haegerich TM, Chou R. CDC guideline for prescribing opioids for chronic pain--United States, 2016. JAMA. 2016;315(15): 1624-1645.

8. Wasan AD, Correll DJ, Kissin I, O'Shea S, Jamison RN. Iatrogenic addiction in patients treated for acute or subacute pain: a systematic review. J Opioid Manag. 2006;2(1):16-22.

9. Boscarino JA, Rukstalis MR, Hoffman SN, et al. Prevalence of prescription opioid-use disorder among chronic pain patients: comparison of the DSM-5 vs. DSM-4 diagnostic criteria. J Addict Dis. 2011; 30(3):185-194.

10. Vlassakov KV, Kissin I. A quest to increase safety of anesthetics by advancements in anesthesia monitoring: scientometric analysis. Drug Des Devel Ther. 2015;9:2599-2608.

11. Jamison RN, Martel MO, Huang CC, Jurcik D, Edwards RR. Efficacy of the opioid compliance checklist to monitor chronic pain patients receiving opioid therapy in primary care. J Pain. 2016;17(4):414-423.

12. Ballentyne JC, Sullivan MD. Intensity of chronic pain--the wrong metric? N Eng J Med. 2016;373(22):2098-2099.

13. Vlassakov KV, Kissin I. Decline in the development of new anesthetics. Trends Pharmacol Sci. 2016;37(5):344-352.

14. cdc.gov [homepage on the Internet]. CDC guideline for prescribing opioids for chronic pain - United States, 2016. MMWR Recommendations and Reports; 2016. Available from: http://www.cdc.gov/mmwr/ volumes/65/rr/rr6501e1.htm. Accessed May 24, 2016.

15. Volkow ND, Frieden TR, Hyde PS, Cha SS. Medication-assisted therapies--tackling the opioid-overdose epidemic. N Engl J Med. 2014; 370(22):2063-2066. 


\section{Publish your work in this journal}

The Journal of Pain Research is an international, peer reviewed, open access, online journal that welcomes laboratory and clinical findings in the fields of pain research and the prevention and management of pain. Original research, reviews, symposium reports, hypothesis formation and commentaries are all considered for publication.
The manuscript management system is completely online and includes a very quick and fair peer-review system, which is all easy to use. Visit http://www.dovepress.com/testimonials.php to read real quotes from published authors. 